\title{
The Bourdon illusion in subjective contours
}

\author{
JAMES T. WALKER and MATTHEW D. SHANK \\ University of Missouri-St. Louis, St. Louis, Missouri
}

\begin{abstract}
The Bourdon illusion is a contour-attraction effect in which a straight edge of a solid figure appears bent in the same direction as an objectively bent edge located nearby. This illusion is stronger in subjective contours than in real contours. A feature-detection model accounts for these findings and other aspects of the Bourdon illusion.
\end{abstract}

The term subjective (or illusory) contours refers to the perception of visual lines or edges in regions that are physically homogeneous, that is, in regions lacking any objective luminance gradients (Kanizsa, 1955, 1979; Ware, 1981). In other words, subjective contours are perceived lines or boundaries that are not physically present. Figure 1A shows a typical subjective figure (Kanizsa, 1955). The subjective triangle has sharp edges, appears brighter than the background, and appears to lie in front of the background in depth. In Figure 1B the subjective contours have been filled in.

Despite the fact that subjective contours are so readily observed, there has been little agreement on the underlying mechanisms (e.g., Frisby \& Clatworthy, 1975; Ginsburg, 1975; Gregory, 1972; Halpern \& Saltzman, 1983; Kanizsa, 1979; Rock \& Anson, 1979; Ware, 1981). Nor is the functional significance of subjective contours entirely clear. Ramachandran (1986a, 1986b) offered the engaging speculation that subjective contours may have evolved as an anticamouflage device that would enhance the visual edges of a spotted predator, such as a leopard, seen against a background of sun-dappled foliage.

In several contexts, real and subjective contours produce similar, although not identical, effects. For example, subjective contours, like real contours, produce visual illusions, such as the Poggendorff (Goldstein \& Weintraub, 1972; Gregory, 1972; Meyer \& Garges, 1979), the Zöllner (Pastore, 1971), the Ponzo (Farné, 1968), and perspective reversal in the Necker cube (Bradley \& Petry, 1977). However, these illusions have been somewhat weaker in subjective contours.

The Bourdon illusion (see Figure 2A) is the apparent inward bending of the straight colinear edges of a solid figure consisting of two slender triangles placed apex to apex (Bourdon, 1902; Rozvany \& Day, 1980). These colinear edges, labeled A and B in Figure 2A, appear bent in the directions of edges $C$ and $D$. Thus, the Bourdon illusion involves the attraction or assimilation of visual contours. In most other visual illusions, opposite effects occur-that is, visual contours tend to repel each other,

This study has profited greatly from the comments and criticisms of two anonymous reviewers, whose contributions we are pleased to acknowledge. The authors' address is: Department of Psychology, University of Missouri-St. Louis, St. Louis, MO 63121.
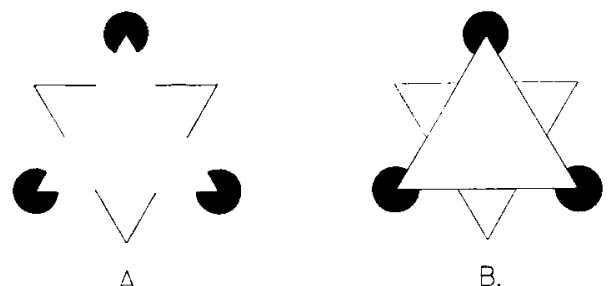

Figure 1. (A) Subjective triangle (after Kanizsa, 1955). (B) Same figure with real outline contours.

as in the Zöllner illusion. Indeed, in the Bourdon illusion as well, repulsion effects are sometimes observed-though not always-when the solid figure is replaced by an outline or by a figure combining dashed and solid lines (Jastrow, 1891; Luckiesh, 1922/1965, p. 92; Rozvany \& Day, 1980; Wenderoth, O'Connor, \& Johnson, 1986a).

Since the Bourdon illusion depends heavily on contour processes, the present study was undertaken to determine whether subjective contours would produce this illusion. Experiment 1 measured the Bourdon illusion in real and subjective contours. Experiment 2 addressed the question of whether the objectively bent edges, as well as the colinear edges, are displaced. In Experiment 3, the illusion figures were rotated $180^{\circ}$-that is, turned upside down, like the inverted example in Figure $2 \mathrm{G}$-in order to assess the possible effects of the location of the bent edges, above or below the colinear edges. Experiment 4 was designed to determine whether the subjective contours themselves were responsible for the Bourdon illusion in the previous experiments, or whether the spatial pattern of the inducing elements-their global disposition in space, apart from their role in creating subjective contours-might have produced the apparent displacements. In Experiment 5, a different measurement procedure was designed to assess the likelihood of a response bias in the preceding measurements of the apparent displacement of the objectively bent edges.

\section{EXPERIMENT 1}

This experiment compared the Bourdon illusion in real and subjective contours. The subjects indicated the extent of apparent bending in a set of illusion figures by 


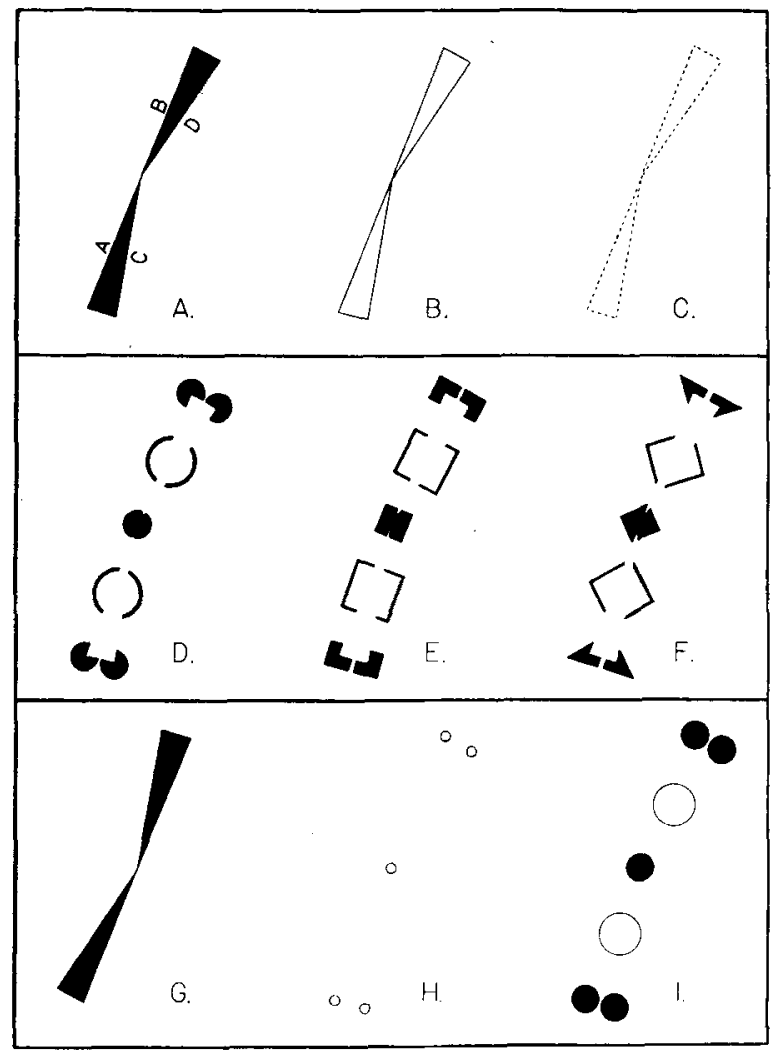

Figure 2. Top panel-Real-contour illusion figures: (A) solid figure; (B) outline; (C) dashed lines. Middle panel-Subjectivecontour figures (D, E, F). Bottom panel-(G) One of the inverted figures in Experiment 3; (H and $I$ ) Control figures in Experiment 4.

choosing among a series of objectively bent comparison stimuli, described below.

\section{Method}

Subjects. Seven male and 5 female undergraduate psychology students at the University of Missouri-St. Louis participated in this experiment for extra course credit. Ages ranged from 18 to 24 , and the mean age was 19.33 years.

Stimuli. The stimuli in this experiment were the illusion figures shown in Figure 2A-F. Each figure consisted of two isosceles triangles having longer sides of 5 in. $(12.7 \mathrm{~cm})$ and apex angles of $12.5^{\circ}$. The figures were oriented as shown, with the colinear edges making an angle of $22.5^{\circ}$ with the vertical. This combination of apex angle and orientation was previously found to produce the strongest illusion (Rozvany \& Day, 1980).

Figure 3 shows the series of 11 comparison stimuli used in judging the apparent bending of the colinear edges in the illusion figures. Comparison 6 , the middle member of the series, was a straight line 10 in. $(25.4 \mathrm{~cm})$ long. This comparison stimulus was oriented parallel to the colinear edges of the illusion figures, that is, rotated $22.5^{\circ}$ clockwise with respect to the vertical. The other comparison stimuli were the same length end to end, but were bent in the middle. Progressing upward and downward from Comparison 6, the amount of bending in successive comparison stimuli increased in $5^{\circ}$ steps. Thus, for comparisons 6 through 11 , the degrees of bending were $0^{\circ}, 5^{\circ}, 10^{\circ}, 15^{\circ}, 20^{\circ}$, and $25^{\circ}$. The long axes of all the comparison stimuli were parallel.

All of the displays were drawn in black ink on white cardboard. The illusion figures were presented at a viewing distance of $2 \mathrm{~m}$, approximately at eye level, on a modified music stand inclined $8.5^{\circ}$ from the vertical. The comparison stimuli were suspended from the lower edge of the stand, and were in a frontoparallel plane. The displays were lit by overhead fluorescent lights. The luminance of the white background was $210 \mathrm{~cd} / \mathrm{m}^{2}$ on the illusion figures and $120 \mathrm{~cd} / \mathrm{m}^{2}$ on the comparison stimuli, as measured by a Macbeth illuminometer. Each illusion figure and comparison stimulus subtended a visual angle of about $7^{\circ}$ measured end to end.

Procedure. To familiarize the participants with subjective contours, they were shown the Kanizsa figure illustrated in Figure 1A. This figure was also shown with real contours replacing the subjective contours, as in Figure 1B. No subject failed to see the subjective triangle. Each subject then viewed all six illusion figures in an individually randomized sequence. For each illusion figure, the subjects indicated which comparison stimulus appeared most similar to the apparent bending of the colinear edges. Subjects were free to use fractional scale values in the comparison series, but only 1 subject did so.

\section{Results and Discussion}

If the Bourdon illusion occurs in the expected direction, then colinear edges $A$ and $B$ (see Figure 2A) will appear displaced inward in the direction of bent edges $C$ and $D$, and in that case, the subject will equate the apparent bending with a comparison stimulus greater than 6 (see Figure 3). If a negative illusion occurs, then the colinear edges will appear bent outward-away from edges $C$ and $D$-and in that case the subject will equate the apparent bending with a comparison stimulus less than 6 . Responses in the expected direction, in degrees of bending, were considered positive, and responses in the other direction were considered negative.

The results were subjected to a repeated measures analysis of variance. There were highly significant differences within the set of six illusion figures $[F(5,55)=22.22$, $p<.001]$. Figure 4 shows the mean illusion in degrees of bending for each figure.

The solid figure produced a mean illusion of $3.75^{\circ}$ $[t(11)=3.45, p<.01]$. This measure compares closely with the values of $3.68^{\circ}$ found by Rozvany and Day (1980) and $3.62^{\circ}$ found by Wenderoth et al. (1986a, Experiment 2 , chevron measurements, $10^{\circ}$ apex angle).

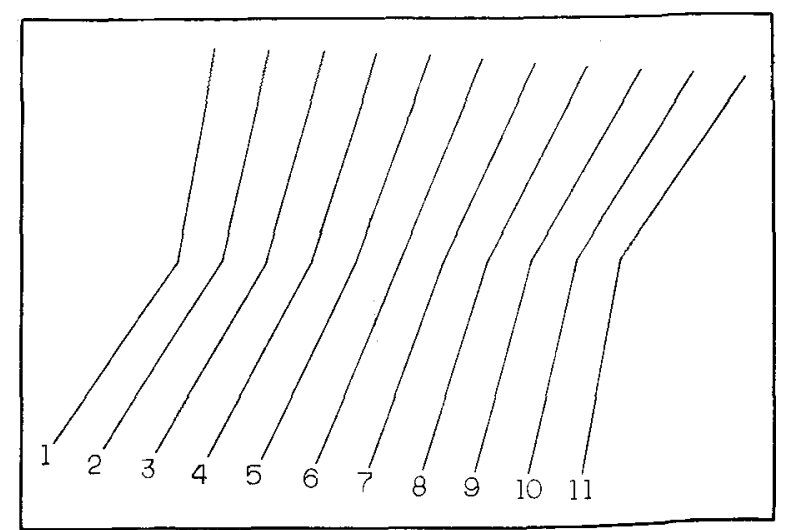

Figure 3. Comparison stimuli in Experiments 1 through 4. Lines are progressively bent in $5^{\circ}$ increments. 


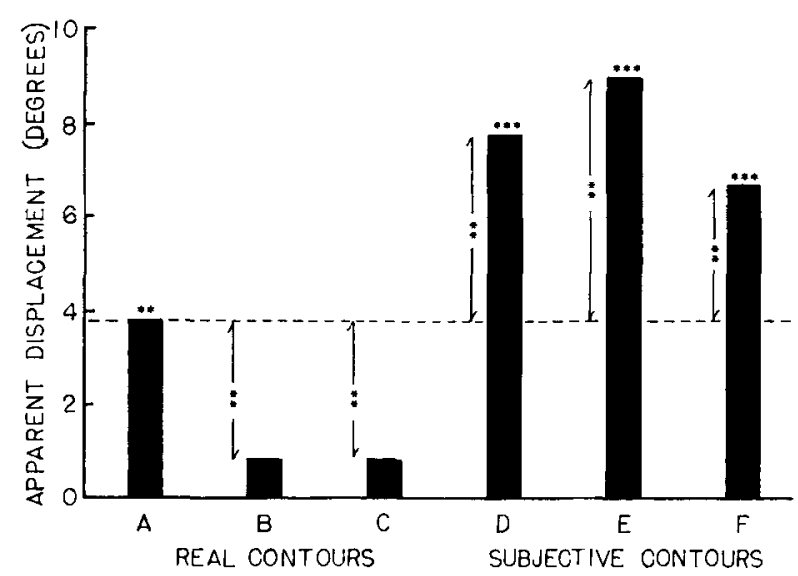

Figure 4. Bourdon illusion in Experiment 1: Mean apparent displacements (in degrees) of bending. Asterisks at tops of bars indicate values significantly different from zero; arrows indicate selected Newman-Keuls comparisons $\left(* * p<.01,{ }^{* * *} p<.001\right)$. Illusion Figures $A$ through $F$ are shown in Figure 2.

Neither the outline nor the dashed figure produced a significant Bourdon illusion in the present experiment, consistent with earlier findings under comparable conditions.

Each of the subjective-contour figures produced an illusion significantly greater than zero [all values of $t(11)$ $\geq 7.09, p<.001]$. Pairwise comparisons were made between means, using the Newman-Keuls procedure. Each of the subjective-contour figures produced a greater illusion than the solid figure, as the arrows in Figure 4 indicate. Within the set of subjective-contour figures there were no significant differences.

In one respect, the present finding of a greater Bourdon illusion in subjective contours may appear paradoxical. In earlier studies, solid figures produced the strongest illusion, and outlines or dashed figures produced weaker illusions or even a reversal of the Bourdon effect (Rozvany \& Day, 1980; Wenderoth et al., 1986a). If reducing a solid figure to an outline weakens or reverses the Bourdon illusion, then subjective contours might be expected to produce little or no illusion, since these contours appear weaker or less compelling than real contours (Halpern, Saltzman, Harrison, \& Widaman, 1983). But in fact, subjective contours produced substantially greater illusions than the solid figure in the present experiment.

In another respect, however, the subjective-contour figures are more closely comparable to the solid figure than to the outlines: The solid and subjective figures are all defined by edges, as opposed to the lines defining the outline figures. In the solid figure, each real edge is a onestep luminance gradient, whereas the lines defining the outline figures are two-step gradients. In subjective figures the edges are also one-step gradients-objective luminance gradients in the immediate regions of the inducing elements, and subjective brightness gradients in the physically homogeneous areas where these contours appear between the inducing elements. If the Bourdon illusion depends on interactions between edges rather than lines, then subjective contours might be expected to produce a larger illusion than an outline figure. But it is not obvious why subjective edges should produce a greater Bourdon illusion than the objective edges of a solid figure. This question is considered further in connection with the feature-detection model proposed in the General Discussion section.

We found an unexpected illusion occurring in the comparison stimuli. In Figure 3, the midpoints of the comparison lines-the points where the lines bend-are aligned horizontally. However, the midpoints of the lines on the right side of the display appear to be located higher than the midpoints on the left. After making the judgments relating to the Bourdon illusion, the subjects were asked to indicate the apparent location of these midpoints. Ten of the 12 subjects indicated that the midpoints-the bends-looked higher on the right $(Z=2.02, p<.05)$.

Since this unexpected illusion involves an apparent vertical displacement of the midpoints of the comparison stimuli, there is no indication that such an effect impairs the usefulness of the comparison stimuli in measuring the Bourdon illusion. Indeed, the comparability of the measurements of the Bourdon illusion in the present experiment and in the earlier studies described above, in which adjustment methods were used, lends credence to the present measurement procedure. The General Discussion section offers a possible explanation for this illusion in the comparison stimuli.

\section{EXPERIMENT 2}

Since the Bourdon illusion involves the attraction or assimilation of colinear edges toward the orientation of bent edges, we are led to ask whether mutual assimilation may occur in a Bourdon figure-that is, do the bent edges appear displaced toward the colinear edges? If mutual assimilation occurs, then the bent edges should appear less bent than they in fact are. Experiment 2 was designed to assess this possibility in real and subjective contours.

\section{Method}

Subjects. Four male and 8 female undergraduate psychology students participated in this experiment for extra course credit. Ages ranged from 18 to 37 , and the mean age was 21.42 years.

Stimuli. The same illusion figures and comparison stimuli were used as in Experiment 1.

Procedure. As in the first experiment, the subjects matched the apparent bending of the colinear lines and edges (A and B in Figure 2A) to one of the comparison stimuli, and, in addition, similarly judged the apparent bending of the objectively bent lines and edges ( $C$ and $D$ in Figure 2A). As in Experiment 1, the subjects were free to choose fractional scale values, but no subject did so. The illusion figures were presented in an individually randomized sequence, and the judgments of the bent and colinear lines were also randomized individually.

\section{Results and Discussion}

The results were subjected to a $2 \times 6$ analysis of variance where the factors were kinds of edges (colinear, bent) and illusion figures (solid, outline, dashes, circles, 


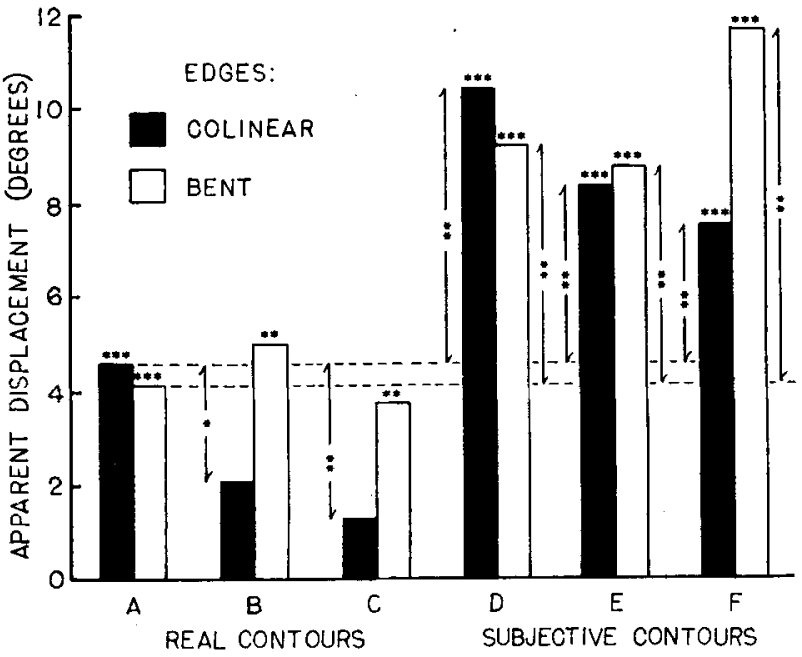

Figure 5. Results of Experiment 2: Bourdon illusion (solid bars) and apparent displacement of bent edges (open bars). ${ }^{*} p<.05$, $* * p<.01,{ }^{* * *} p<.001$.

squares, diamonds). There were repeated measures on both factors. The kinds of illusion figures produced a highly significant effect, as in Experiment $1[F(5,55)=$ $43.88, p<.001]$. There was no significant difference between the apparent displacement of the colinear and bent edges $[F(1,11)=2.08, p<.25]$, nor was there any significant edge $\times$ figure interaction $[F(5,55)=2.03$, $p<.10$ ]. Figure 5 shows the mean apparent displacements in degrees for each illusion figure.

In the main, the results for the colinear edges are comparable to the results of Experiment 1. Among the realcontour figures, only the solid figure produced a significant Bourdon illusion $[t(11)=4.75, p<.001]$. All of the subjective-contour figures produced significant Bourdon illusions [all values of $t(11) \geq 7.42, p<.001$ ]. By Newman-Keuls procedure, each of the subjective-contour figures produced a greater Bourdon illusion and a greater displacement of the bent edges than the solid figure, as the arrows indicate in Figure 5.

The bent edges appeared significantly displaced in all of the real-contour figures [all values of $t(11) \geq 3.45$, $p<.01]$, and in the subjective-contour figures $[t(11) \geq$ $6.77, p<.001]$. By Newman-Keuls tests, the displacements of these edges were greater in all of the subjective figures than in the solid figure, which did not differ from the outline or from the dashed figure. However, a difficulty arises in interpreting the apparent displacements of the bent edges.

If the bent edges appeared to be attracted in the direction of the colinear edges, then a subject would match these edges to a comparison stimulus less than 11. But a repulsion effect in the bent edges-had there been anycould not have been indicated, since there was no comparison stimulus showing more than $25^{\circ}$ of bending. Furthermore, in the absence of any apparent displacement of the bent edges, any tendency of subjects to avoid the end member of the comparison series would introduce a response bias that would be mistaken for an attraction effect. Experiment 5 addressed this issue using a different measurement method.

The possible response bias in the apparent displacement of the bent edges does not apply to the measurements of the Bourdon illusion, that is, to the apparent displacement of the colinear edges. If there were no Bourdon illusion, then a subject would be expected to match the colinear edges to Comparison Stimulus 6. Because this comparison stimulus is the middle member of the series, the subject would be free to choose a higher or lower value in the absence of the Bourdon illusion. If a positive illusion occurred, then the apparent displacement of the colinear edges would match a comparison stimulus greater than 6. A negative Bourdon illusion, repulsion effect, would result in a match less than 6 . Thus, there is no difficulty in interpreting the measurements of the Bourdon illusion.

The illusion in the comparison stimuli observed in Experiment 1 also occurred here. The midpoints of the comparison lines on the right appeared higher to 11 of the 12 subjects $(Z=2.60, p<.01)$.

\section{EXPERIMENT 3}

In Experiments 1 and 2, the illusion figures were oriented as shown in Figure 2. The colinear edges always formed the upper left boundary of each figure, and thus were consistently located above the objectively bent edges. In the present experiment, the illusion displays were inverted so that the bent edges formed the upper left boundary of each figure (see the inverted example in Figure 2G). The orientation of the colinear edges remained the same as in the previous experiments, namely $22.5^{\circ}$ clockwise from the vertical. Thus, Experiment 3 was designed to assess the possible effects of interchanging the upper and lower boundaries of the illusion figuresthat is, placing the colinear edges below the bent edges.

\section{Method}

Subjects. Seven male and 5 female undergraduate psychology students received extra course credit for their participation. Ages ranged from 18 to 23 , and the mean age was 19.08 years.

Stimuli. The same illusion figures were used as in Experiments 1 and 2, except here the figures were inverted as in the example in Figure 2G. The same comparison stimuli were used in the same orientation as in the two previous experiments.

Procedure. With the exception of inverting the illusion displays in this experiment, the same procedures were used as in Experiments 1 and 2. Subjects were free to choose fractional scale values in judging the illusion figures, and 3 subjects did so.

\section{Results and Discussion}

The results were subjected to a two-way repeated measures analysis of variance, as in Experiment 2. The kinds of illusion figures produced a highly significant effect $[F(5,55)=14.99, p<.001]$. The kinds of edges (colinear and bent) produced no significant effect $[F(1,11)$ $=3.75, p<.10$ ], but the edge $\times$ figure interaction was 


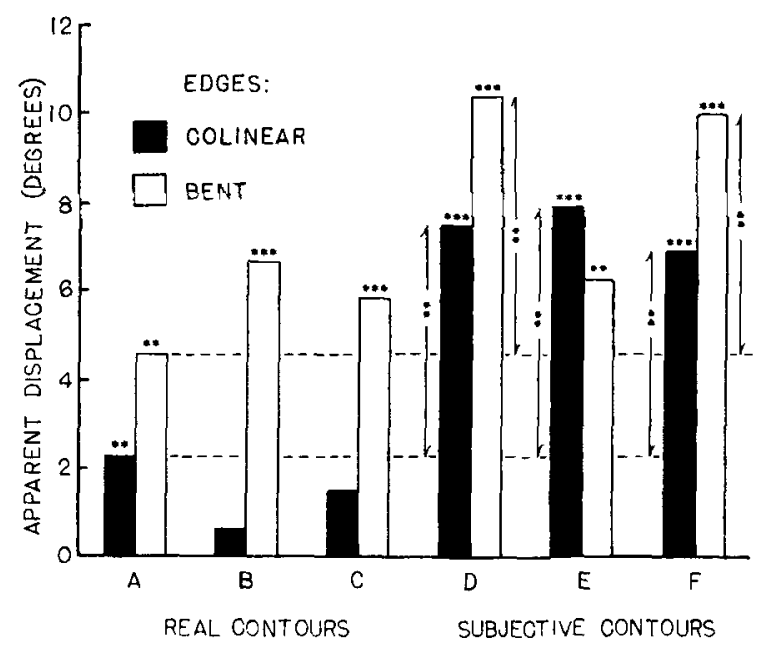

Figure 6. Results of Experiment 3, inverted figures: Bourdon illusion (solid bars) and apparent displacement of bent edges (open bars). ${ }^{* *} p<.01,{ }^{* * *} p<.001$.

significant $[F(5,55)=3.18, p<.05]$. In the real-contour figures, only the solid figure produced a significant Bourdon illusion, although the bent edges were significantly displaced in all three of these figures. As in the earlier experiments, subjective contours producer greater effects. The arrows in Figure 6 show the Newman-Keuls comparisons between the solid figure and all others for the apparent displacement of the bent and colinear edges.

Overall, the present results are comparable to the pattern of results in Experiment 2. Thus, it makes little difference whether the colinear edges form the upper or lower boundary of an illusion figure. The same possibility of a response bias in judging the apparent displacement of the bent edges arises here as in Experiment 2, an issue considered further in Experiment 5.

The comparison stimuli produced the same illusion here as in the previous two experiments. Ten of the 12 subjects in this experiment reported that the midpoints of the comparison lines on the right side of the display appeared higher than the midpoints on the left side $(Z=2.02$, $p<.05$ ).

\section{EXPERIMENT 4}

In the previous experiments, the Bourdon illusion occurred in the presence of subjective contours, but it is not entirely clear that the subjective contours were the sole factor in producing the illusion. Consider Figure 2D, for example, where the inducing elements consist of notched disks and broken circles. The inducing elements themselves-apart from their role in generating subjective contours-constitute a pattern having some features of a Bourdon illusion figure. If the notched disks were filled in, and if the broken circles were completed, would the resulting pattern produce the Bourdon illusion-that is, would the imaginary straight line connecting the three colinear disks appear bent in the absence of any subjective contours? Experiment 4 was designed to assess this possibility.

\section{Method}

Subjects. The subjects were 6 male and 6 female undergraduate students who received extra course credit for their participation. Ages ranged from 18 to 22 years, and the mean age was 18.92 .

Stimuli. Figure 2D (subjective contours) and Figures $2 \mathrm{H}$ and $2 \mathrm{I}$ (controls) were used in this experiment. Figures 2A, 2B, and 2C (real contours) were also used.

Control Figure $\mathrm{H}$ consisted of small outline circles centered on the same locations as the corners and middle of the illusion figures. In this control figure, an imaginary straight line can be drawn through three of the circles, thus forming the upper boundary of an imaginary Bourdon figure. This imaginary line is oriented parallel to the colinear edges of the real-contour and subjective-contour illusion figures. An imaginary bent line can be drawn connecting the middle circle with the other two circles at the ends of the figure, thus forming the lower boundary of the imaginary illusion figure.

Control Figure I consisted of solid black disks and unbroken outline circles centered in the same locations as the notched disks and broken circles in Subjective-Contour Figure D. In this control figure, three of the solid black disks are aligned with each other. An imaginary straight line forming the upper colinear boundaries of a Bourdon figure can be drawn tangent to these three disks and also tangent to the outline circles. An imaginary bent line forming the lower boundaries of the illusion figure can be drawn tangent to the middle black disk, the outline circles, and the other black disks at the corners of the pattern. Thus, the imaginary lines in both control figures display the same orientations as the real and subjective contours in the illusion figures. If these control figures produce the Bourdon illusion, then the imaginary colinear lines will appear displaced toward the imaginary bent lines.

Procedure. Except for judgment of the control figures, the same procedures were used as in the previous experiments. In judging Control Figure $\mathbf{H}$, the subjects were instructed to connect the three colinear circles with an imaginary line, and to match the apparent bending of that line to one of the comparison stimuli. The subjects also matched the imaginary bent line to a comparison stimulus. As in the preceding experiments, subjects were free to choose fractional scale values in the series of comparison stimuli, and 4 subjects did so. In judging Control Figure I, similar matches were made for the upper and lower imaginary tangent lines. Each subject judged the control figures and illusion figures intermixed in an individually randomized sequence, and the judgments of the bent and colinear lines were also randomized.

\section{Results and Discussion}

The results were subjected to a repeated measures analysis of variance, as in the earlier experiments. There were highly significant effects of figures $[F(5,55)=5.74$, $p<.001]$ and edges $[F(1,11)=27.35, p<.001]$, and a highly significant figure $\times$ edge interaction $[F(5,55)=$ $10.50, p<.001]$.

Figure 7 shows the results in degrees of apparent displacement. The imaginary colinear edges in Control Figure $\mathrm{H}$ showed a small but significant negative Bourdon illusion-that is, those edges were displaced away from the imaginary bent edges $[t(11)=-2.35, p<.05]$. In Control Figure I, the imaginary colinear edges showed no significant displacement $(t<1)$. The subjectivecontour figure produced a highly significant Bourdon illusion $[t(11)=9.84, p<.001]$, which differed signifi- 


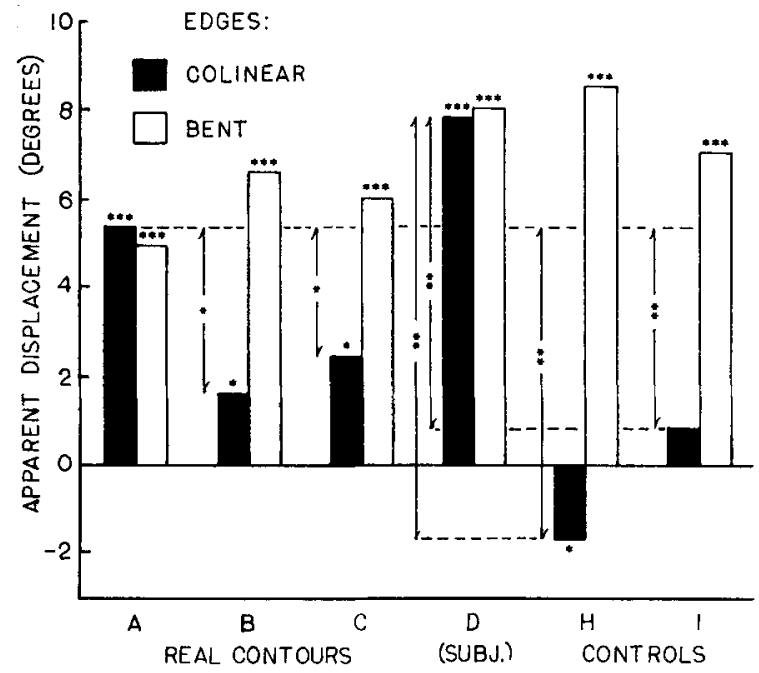

Figure 7. Results of Experiment 4: (A, B, C) Real contours; (D) subjective contours; $(\mathrm{H}, \mathrm{I})$ control figures. ${ }^{*} p<.05, * * p<.01$, $* * * p<.001$.

cantly from the displacements of the imaginary colinear edges in both control figures by Newman-Keuls tests $(p<.01)$. The imaginary bent edges in both control figures appeared displaced in the direction of the colinear edges, like the bent edges in all the other figures.

In the present experiment, there was a small negative Bourdon illusion in one of the control figures and no significant illusion in the other. Thus, the Bourdon illusion in the subjective-contour figure could not have been due merely to the spatial location or configuration of the contour-inducing elements in that figure.

The apparent displacements of the bent edges in this experiment are subject to the same possible response bias described earlier. Experiment 5 addressed this problem, using a different measurement procedure.

The comparison stimuli produced the same illusion as in the three preceding experiments. For 11 of the 12 subjects, the midpoints of the comparison lines on the right side of the display appeared higher than those on the left side $(Z=2.60, p<.01)$.

\section{EXPERIMENT 5}

This experiment used a different procedure to measure the Bourdon illusion and the apparent displacement of the objectively bent edges. The new measurement procedure was designed to reduce or eliminate the possible response bias in the previous judgments of the bent edges.

\section{Method}

Subjects. One male and 11 female undergraduate psychology students participated for extra course credit. Ages ranged from 18 to 41 , and the mean age was 25.42 .

Stimuli. Three illusions were used: the solid, outline, and subjective-contour figures shown in Figures 2A, 2B, and 2D. Figure 8 shows the comparison stimuli. The middle member of the comparison series was a straight line of the same length and orien- tation as the illusion figures. The other comparison stimuli were bent $25^{\circ}$ and $50^{\circ}$ to the left and right. From left to right, the comparison stimuli were labeled $20 \mathrm{~L}, 10 \mathrm{~L}, 0,10 \mathrm{R}$, and $20 \mathrm{R}$.

The illusions and comparison stimuli, drawn in black ink on white backgrounds, were presented in a frontoparallel plane at a viewing distance of $2 \mathrm{~m}$. Each illusion figure was presented approximately at eye level, and the comparison stimuli were located directly below. Overhead fluorescent lights provided background luminances of $174 \mathrm{~cd} / \mathrm{m}^{2}$ on the illusion figures and $131 \mathrm{~cd} / \mathrm{m}^{2}$ on the comparison stimuli, as measured by a Macbeth illuminometer.

Procedure. As in the preceding experiments, all of the subjects were first shown the Kanizsa triangle and the filled-contour version of that figure illustrated in Figure 1. For practice in using the comparison stimuli, each subject then judged the apparent bending of a set of four objectively bent lines. The objective bending of the practice lines, in degrees, was $37.5 \mathrm{~L}, 12.5 \mathrm{~L}, 12.5 \mathrm{R}$, and $37.5 \mathrm{R}$. The practice lines were presented in an individually randomized sequence. The subjects were instructed to match the apparent bending of each practice line to a scale value on the dimension of comparison stimuli, interpolating as necessary. Each subject then judged the three illusion figures in an individually randomized sequence, using the comparison stimuli to indicate the apparent bending of the colinear and objectively bent edges.

If there were no Bourdon illusion, then a subject would match the colinear edges to the straight comparison stimulus, labeled 0 in Figure 8. If a positive Bourdon illusion occurred, then the subject would judge the colinear edges as bending in the direction of the comparison stimuli on the right of the display ( $10 \mathrm{R}$ and $20 \mathrm{R}$ ), and if a negative illusion occurred, these edges would appear bent in the other direction.

If there were no apparent displacement of the objectively bent edges, then a subject would match these edges to Comparison Stimulus $10 \mathrm{R}$. If the bent edges appeared displaced toward the colinear edges, then the subject would assign the bent edges a scale value less than $10 \mathrm{R}$. If the bent edges appeared displaced away from the colinear edges, then the subject would choose a scale value greater than $10 \mathrm{R}$. Thus, the present comparison stimuli would allow the measurement of repulsion as well as attraction, or assimilation, of the bent edges by the colinear edges, thereby eliminating or reducing the possible response biases in these measurements described in the earlier experiments.

\section{Results and Discussion}

The results were subjected to a $2 \times 3$ repeated measures analysis of variance where the factors were kinds of edges (colinear, bent) and illusion figures (solid, outline, subjective). There were significant effects of edges $[F(1,11)$ $=5.49, p<.05]$ and figures $[F(2,22)=48.20$,

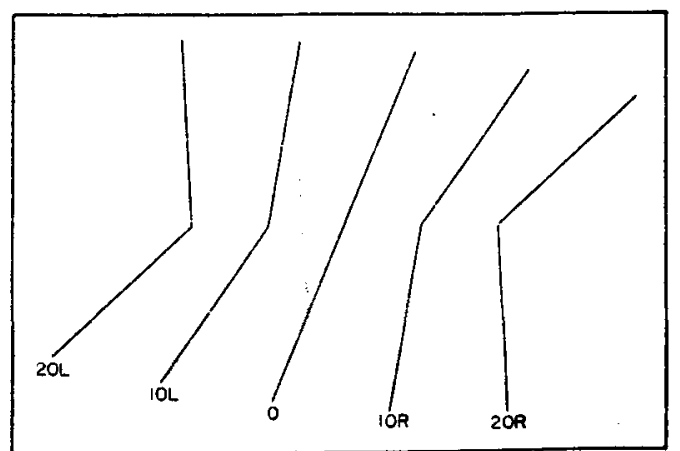

Figure 8. Comparison stimuli in Experiment 5. Lines are progressively bent in $25^{\circ}$ increments. 


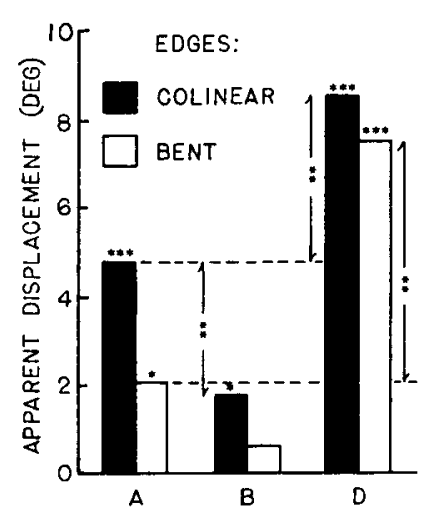

Figure 9. Results of Experiment 5: (A) Solid figure; (B) outline; (D) subjective contours. ${ }^{*} p<.05,{ }^{* *} p<.01,{ }^{* * *} p<.001$.

$p<.001$ ], but there was no edge $\times$ figure interaction $(F<1)$. The simple effect of edges was significant for the solid figure $[F(1,11)=5.04, p<.05]$, but not for the outline or the subjective figure (both $F \mathrm{~s}<1$ ). Thus, the main effect of edges was due principally to the difference between the apparent displacement of the colinear and bent edges in the solid figure.

Figure 9 shows the apparent displacements for each illusion figure. The solid figure produced a Bourdon illusion of $4.80^{\circ}$, significantly different from zero $[t(11)=$ $7.37, p<.001]$. The outline and subjective-contour figures produced significant Bourdon effects of $1.78^{\circ}$ and $8.55^{\circ}$, respectively $[t(11)=2.54, p<.05$, and $t(11)$ $=13.15, p<.001]$. By the Newman-Keuls procedure, the Bourdon illusion differed significantly in all pairwise comparisons among the three illusion figures $(p<.01)$. These measurements of the Bourdon illusion compare closely with the earlier results in this study, even though the present experiment used a different measurement procedure.

The bent edges in the solid and subjective-contour figures appeared significantly displaced toward the colinear edges $[t(11)=2.59, p<.05$, and $t(11)=$ $17.23, p<.0011$, but the outline figure produced no such effect $(t<1)$. By Newman-Keuls tests, the solid and outline figures did not differ in their effects on the bent edges, but each differed from the subjective figure $(p<.01)$. Thus, the apparent displacements of the bent edges in the present experiment differed from some of the displacements measured earlier.

To facilitate comparisons, the present measurements and the pooled results of Experiments 2 and 4 are shown in Table 1. Because the illusion figures were inverted in Experiment 3, those results are not included in the present comparisons. For the Bourdon illusion, there were no significant differences between the present measures and the pooled results of Experiments 2 and 4 (all values of $t<1$ ).

The displacement of the bent edges in the outline figure was essentially zero in the present experiment $(t<1)$. These edges were significantly displaced in the solid figure $[t(11)=2.59, p<.05]$, but the apparent displacement here was significantly smaller than the pooled measures in Table $1\left[2.08^{\circ}\right.$ vs. $\left.4.58^{\circ} ; t(34)=2.46, p<.05\right]$. In light of these results, it seems likely that the response bias described earlier accounts for the apparent displacement of the bent edges in the outline figures in the previous experiments, and may account partly for the displacement of these edges in the solid figure.

The bent edges in the subjective figure were significantly displaced in the present experiment $[t(11)=17.23$, $p<.001]$. This displacement did not differ significantly from the pooled results in Table $1\left[7.50^{\circ} \mathrm{vs.} 8.65^{\circ} ; t(34)\right.$ $=1.03]$. To the extent that the present measures are free of the response bias described earlier, the apparent displacement of the bent edges observed previously in the subjective figures cannot be attributed wholly to response bias. Thus, all of these results support the notion of mutual attraction between subjective edges in the Bourdon illusion.

\section{GENERAL DISCUSSION}

The comparison stimuli used in four of the present experiments produced an unexpected illusion: The midpoints of the comparison lines on the right side of the display appeared higher than the midpoints on the left. Pooling these results, 42 of the 48 subjects saw this illusion $(Z=5.05, p<.001)$. Since the axes of all the comparison stimuli were tilted $22.5^{\circ}$ clockwise from the vertical, it may be that the subjective vertical was also displaced in that direction. If the subjective horizontal were similarly rotated, then horizontally aligned points would

Table 1

Comparisons Between Experiment 5 and Experiments 2 and 4 (Pooled): Means and Standard Deviations (in Degrees) of Apparent Displacement

\begin{tabular}{|c|c|c|c|c|c|c|c|}
\hline & & \multicolumn{3}{|c|}{ Bourdon Illusion } & \multicolumn{3}{|c|}{ Bent Edges } \\
\hline & & Solid & Outline & Subjective & Solid & Outline & Subjective \\
\hline $\begin{array}{l}\text { Experiments } 2 \text { and } 4 \\
\text { (Pooled } N=24 \text { ) }\end{array}$ & $\begin{array}{l}\text { Mean } \\
S D\end{array}$ & $\begin{array}{l}5.00 \ddagger \\
3.21\end{array}$ & $\begin{array}{l}1.88 \dagger \\
2.88\end{array}$ & $\begin{array}{l}9.17 \ddagger \\
3.27\end{array}$ & $\begin{array}{l}4.58 \ddagger \\
2.92\end{array}$ & $\begin{array}{l}5.83 \ddagger \\
4.08\end{array}$ & $\begin{array}{l}8.65 \ddagger \\
3.68\end{array}$ \\
\hline $\begin{array}{l}\text { Experiment } 5 \\
(N=12)\end{array}$ & $\begin{array}{l}\text { Mean } \\
S D\end{array}$ & $\begin{array}{l}4.80 \ddagger \\
2.25\end{array}$ & $\begin{array}{l}1.78^{*} \\
2.40\end{array}$ & $\begin{array}{l}8.55 \ddagger \\
2.25\end{array}$ & $\begin{array}{l}2.08^{*} \\
2.78\end{array}$ & $\begin{array}{r}.62 \\
3.22\end{array}$ & $\begin{array}{l}7.50 \neq \\
1.51\end{array}$ \\
\hline $\begin{array}{l}\text { Experiment } 5 \text { vs. } \\
\text { Experiments } 2 \text { and } 4\end{array}$ & $t(34)$ & .19 & .10 & .59 & $2.46^{*}$ & $3.85 \ddagger$ & 1.03 \\
\hline
\end{tabular}


appear higher on the right side of the display. Thus, the illusion might be due to a frame-of-reference effect (e.g., Gibson \& Radner, 1937a, 1937b). It is also possible that some features of the Poggendorff illusion play a role in the present illusion (for a variant of the Poggendorff that may apply here, see Coren \& Girgus, 1978 , p. 60 , and Pressey \& den Heyer, 1968).

The Bourdon illusion in the present study occurred in solid figures, but there was little or no illusion in outline figures, consistent with earlier findings (Rozvany \& Day, 1980; Wenderoth et al., 1986a). Experiment 1 demonstrated the Bourdon illusion in three subjective-contour figures, each of which produced a significantly greater illusion than a solid figure having real contours. In the remaining experiments, subjective contours consistently produced a greater Bourdon illusion, although not significantly so in Experiment 4 . The absence of the Bourdon illusion in the control figures in Experiment 4 shows that the illusion in the subjective-contour figures could not have resulted from the mere location or configuration of the contour-inducing elements, as opposed to their role in producing subjective contours.

The present study also attempted to assess the apparent displacement of the objectively bent edges toward the colinear edges. Because of the probable response bias described earlier, the apparent displacements of the bent edges are open to question in the earlier experiments in this study. But the results of Experiment 5, based on a different measurement procedure, indicate that significant displacements of the bent edges occurred in the solid and subjective figures. Thus, there is mutual attraction or as- similation between the bent and colinear edges in the Bourdon illusion.

We offer two possible explanations of the Bourdon illusion: a cognitive model based on confusion, and a model based on interactions between feature detectors. Each explanation attempts to account for the large illusion occurring in subjective contours, the smaller illusion in a solid figure, and the near absence of any effect in outline figures.

In judging the apparent bending of the colinear edges of a solid figure, the subject may confuse the orientation of these edges with the orientation of the bent edges, and vice versa. But in judging the lines of an outline figure, little or no apparent displacement occurs. It may be that less confusion occurs in judging the orientation of a line, because a line consists of two luminance gradients, whereas an edge has only a single gradient. Thus, a line contains more contour information and may represent a stronger feature than an edge. Indeed, lines have been shown to produce greater figural aftereffects than edges (Köhler \& Wallach, 1944).

As we noted earlier, the boundaries of subjective illusion figures are edges rather than lines. Furthermore, subjective edges do not appear as compelling or well defined as the real edges of a solid figure (Halpern et al., 1983). Thus, there may be greater confusion between the orientation of the edges in a subjective figure, and hence a greater Bourdon illusion and greater apparent displacement of the objectively bent lines as well.

Figure 10 represents a model that accounts for the observed effects in terms of the properties of feature detec-

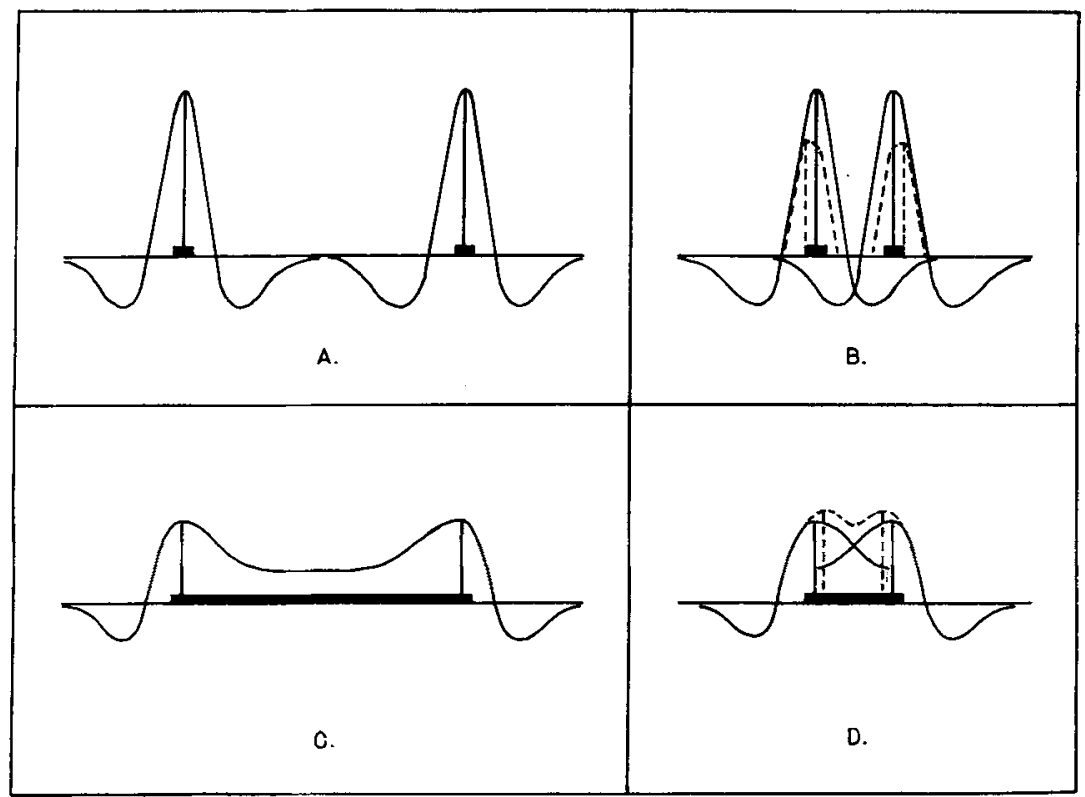

Figure 10. A model accounting for interactions between lines and edges. In each panel, the horizontal axis represents spatial orientation, and the vertical axis represents neural excitation and inhibition. Top panels - Interactions between lines: $(A)$ widely separated lines do not interact; (B) dotted lines show mutual repulsion of more closely spaced lines. Bottom panels-Interactions between edges: (C) widely separated edges do not interact; (D) dotted lines show mutual attraction of more closely spaced edges. 
tors encoding the orientation of lines and edges (e.g., Hubel \& Wiesel, 1968). The horizontal axis in each panel represents a neural substrate encoding spatial orientation. The vertical dimension represents neural activityexcitation above the horizontal axis and inhibition below. The location of a peak of excitation on the horizontal dimension determines the perceived orientation of a line or edge. We will first apply the model to real lines and edges, and then to subjective edges.

Panel A shows two lines that are widely separated in orientation and hence do not interact. Panel B shows real lines that are more closely spaced on the orientation dimension. These lines mutually inhibit each other to some extent, resulting in the mutual repulsion of their peaks of excitation, as shown by the dotted lines. If the lines were so close together that their excitatory peaks overlapped, then the lines would show an attraction or assimilation effect, rather than repulsion. Thus, the interaction between lines changes from repulsion to attraction as their orientations become more similar, and at some particular difference in orientation there should be no apparent displacement at all.

Similar models have been proposed to explain displacements of real contours in several other contexts, such as simultaneous illusions and figural aftereffects (e.g., Coren \& Girgus, 1978, p. 90; Day, 1962; Ganz, 1966; Osgood \& Heyer, 1952; von Békésy, 1967; Wenderoth, O'Connor, \& Johnson, 1986b). In addition, Smith and Over (1975) have explained tilt aftereffects in subjective contours in terms of the adaptation of feature detectors.

Panel C represents a cross-section of a solid figure having real edges widely separated in orientation, like the lines in Panel A. The edges here do not interact. The peak of excitation at each edge represents a Mach band (Ratliff, 1965). In Panel D, the edges are spaced as closely on the orientation dimension as the lines above in Panel $\mathbf{B}$. The peaks of excitation of the edges in Panel D are displaced toward each other, as the dotted lines show. Thus, the edges are attracted toward each other at the same separation that produces repulsion of the lines in Panel B. At some particular smaller separation in orientation, there would be no displacement of the lines-neither attraction nor repulsion-but there would be greater attraction between the edges. For interacting edges, the model predicts only attraction, but for interacting lines, the model predicts attraction at very small differences in orientation and repulsion at larger separations.

Extending this model to subjective contours, if subjective edges excited more broadly tuned feature detectors, then the excitatory and inhibitory regions associated with subjective edges would cover wider portions of the orientation dimension. Thus, subjective edges would exhibit greater attraction than real edges or lines across any given separation, thereby producing a larger Bourdon illusion and greater apparent displacement of the bent edges as well.

The present model, however, is not without its difficulties. Explanations of subjective contours based on feature detectors have been criticized because subjective contours sometimes fail to occur in situations where appropriately oriented feature detectors are surely stimulated (e.g., Gregory, 1972; Halpern \& Saltzman, 1983). If feature detectors play a questionable role in producing subjective contours, then their role in explaining any process occurring in subjective contours is also open to question. Nevertheless, the present model may have some heuristic value.

Although the feature-detection model is highly speculative, it seems more promising in some respects than the confusion model described above. The confusion model makes no prediction of any repulsion effect, or negative illusion, in the outline figure, although weak repulsion effects are sometimes observed. On the other hand, the feature-detection model predicts repulsion effects at some differences in orientation between the colinear and bent lines in an outline figure. For a solid figure, the model predicts no repulsion effects under any conditions, consistent with the observed results in the present study and other studies as well (Rozvany \& Day, 1980; Wenderoth et al., 1986a). Thus, the feature model provides a greater degree of specificity, and greater consistency with empirical findings.

To summarize, the present experiments have demonstrated the Bourdon illusion in subjective contours. Indeed, this illusion was greater in subjective contours than in real contours, and so was the apparent displacement of the bent edges of a Bourdon figure. Earlier studies found other illusions weaker in subjective contours (e.g., Goldstein \& Weintraub, 1972; Meyer \& Garges, 1979). However, those weaker illusions were produced partly by subjective and partly by real contours. The greater magnitude of the present subjective-contour illusions may be due to the fact that these illusions resulted wholly from interactions between subjective contours. A featuredetection model, although speculative and open to criticism, offers consistent explanations of the observed results.

\section{REFERENCES}

Bourdon, B. (1902). La perception visuelle de l'espace. Paris: Reinwald.

Bradley, D. R., \& PeTry, H. M. (1977). Organizational determinants of subjective contour: The subjective Necker cube. American Journal of Psychology, 90, 253-262.

COREN, S., \& GIRGUS, J. S. (1978). Seeing is deceiving: The psychology of visual illusions. Hillsdale, NJ: Erlbaum.

DAY, R. H. (1962). Excitatory and inhibitory processes as the basis of contour shift and negative after-effect. Psychologia, 5, 185-193.

FARNÉ, M. (1968). Aclune osservazioni con linee virtuali e margini quasi percettivi. Bolletino della Societa Italiana di Biologia Sperimentale, 44, 1613-1616.

Frisby, J. P., \& Clatworthy, J. L. (1975). Illusory contours: Curious cases of simultaneous brightness contrast? Perception, 4, 349-357.

GANZ, L. (1966). Mechanism of the figural aftereffect. Psychological Review, 73, 128-150.

GIBSON, J. J., \& RADNER, M. (1937a). Adaptation, after-effect, and contrast in the perception of tiked lines: I. Quantitative studies. Joumal of Experimental Psychology, 20, 453-467.

GiBson, J. J., \& RADNER, M. (1937b). Adaptation, after-effect, and 
contrast in the perception of tilted lines: II. Simultaneous contrast and the areal restriction of the after-effect. Journal of Experimental Psychology, 20, 553-569.

GiNSBURG, A. P. (1975). Is the illusory triangle physical or imaginary? Nature, 257, 219-220.

Goldstein, M. B., \& Weintraub, D. L. (1972). The parallel-less Poggendorff: Virtual contours put the illusion down but not out. Perception \& Psychophysics, 11, 353-354.

Gregory, R. L. (1972). Cognitive contours. Nature, 238, 51-52.

Halpern, D., \& Saltzman, B. (1983). The multiple determination of illusory contours: 1. A review. Perception, 12, 281-291.

Halpern, D., Saltzman, B., Harrison, W., \& Widaman, K. (1983). The multiple determination of illusory contours: 2 . An empirical investigation. Perception, 12, 293-303.

Hubel, D. H., \& WIESEL, T. N. (1968). Receptive fields and functional architecture of monkey striate cortex. Journal of Physiology, 195, 215-243.

JASTROW, J. (1891). A study of Zöllner's figures and other related illusions. American Journal of Psychology, 4, 381-398.

Kanizsa, G. (1955). Margini quasi-percettivi in campi con stimolazione omogenea. Rivista di Psicologia, 49, 7-30.

Kanizsa, G. (1979). Organization in vision. New York: Praeger.

KöHLER, W., \& WaLLACH, H. (1944). Figural after-effects: An investigation of visual processes. Proceedings of the American Philosophical Society, 88, 269-357.

LUCKIESH, M. (1965), Visual illusions. New York: Dover. (original work published by Van Nostrand and Constable, 1922)

Meyer, G. E., \& GARges, C. (1979). Subjective contours and the Poggendorff illusion. Perception \& Psychophysics, 26, 302-304.

OSGOOD, C. E., \& HEYER, A. W. (1952). A new interpretation of figural aftereffects. Psychological Review, 59, 98-118.
PASTORE, N. (1971). Selective history of theories of visual perception. New York: Oxford University Press.

Pressey, A. W., den Heyer, K. (1968). Observations on Chiang's "new" theory of geometrical illusions. Perception \& Psychophysics, 4, 313-314.

Ramachandran, V. S. (1986a). Capture of stereopsis and apparent motion by illusory contours. Perception \& Psychophysics, 39, 361-373.

RAMACHANDRAN, V. S. (1986b). What does the brain do with illusory contours? Perception \& Psychophysics, 39, 216.

RATLIFF, F. (1965). Mach bands: Quantitative studies on neural networks in the retina. New York: Holden-Day.

Rock, I., \& ANSON, R. (1979). Illusory contours as the solution to a problem. Perception, 8, 665-681.

Rozvany, G. I. N., \& DAY, R. H. (1980). Determinants of the Bourdon effect. Perception \& Psychophysics, 28, 39-44.

Smith, A., \& Over, R. (1975). Tilt aftereffects with subjective contours. Nature, 257, 581-582.

voN BÉkÉsY, G. (1967). Sensory inhibition. Princeton, NJ: Princeton University Press.

WARE, C. (1981). Subjective contours independent of subjective brightness. Perception \& Psychophysics, 29, 500-504.

Wenderoth, P., O'Connor, T. O., \& Johnson, M. (1986a). Expansion and contraction of outline and solid acute angles: Effects of angle magnitude, type of display, and the nature of the matching task. Perception \& Psychophysics, 39, 261-266.

Wenderoth, P., O'ConNor, T. O., JohnSon, M. (1986b). The tilt illusion as a function of the relative and absolute lengths of test and inducing lines. Perception \& Psychophysics, 39, 339-345.

(Manuscript received March 17, 1986; revision accepted for publication January 12, 1987). 